THE BIVIUM SYNDROME IN THE HISTORY OF SEMIOTICS*

\author{
Luigi Bomeo \\ University of Coloracio
}

Recent interest in the history of semiotics has begun to generate some concern for the theoretical framework housing the development of the discipline in relation to thinkers who have been pondering the nature and function of the sign in Nestern scholarship (e.g., Jakobson 1975; Sebeok 1977:149-188). Among the problems immediately surfacing to the attention of the aspiring historian of semiotics, there are three which stand out for their difficulty of content, boundaries, and methodology.

First of all, what should one consider for inclusion in the history of semiotics? The question is loaded with so many variables that it is extremely difficult to delineate an answer on which two persons might agree, for the history of semiotics is, at its most comprehensive level, a history of human intelligence. In other words, any suggested answer will reflect, undoubtedly, each individual's conception of semiotics. Nevertheless, whenever at least two people agree

\footnotetext{
* This lecture, given at an informal gathering of University of Colorado colleagues in the Spring of 1977, was recorded and transcribed by Dr. Hope Hamilton-Faria. It replects, thus, the oral style as delfvered by the author.
} 
56

$-P 2-$

on one answer, they create thereby a tistorical basis for an opinion which, correlated with mary others, may result in a wide gamut of 'contents' ranping from the narrowness of iul it Kristeva's sémiotique to Umberto Fco's 'imperiazistic', it: not 'cosmic', semiotica.

Of course, if one accepts Kristeva's view basically confined to literary criticism, where 'semiotics' plays the role of a different term for a variety of 'structura?ism', the task for inventorizing contents on the basis of 'apit-prop' ideolopy would not be discouraging, even by tossing into Kristevg's 'semiotic box' a fer trimmings such as cinemetography, choreoG,raphy, or aeroacrobatism. When one moves, however, to the other end of the spectrum housing, philosophy as the comerstone of mankind's civilization, naturally the task becomes disheartening at the ideal level.

The contents in question, thus, reflect arything, dealine, with the concept of the sipn. Since it is rather difficult at present to start with the squtus naturae (in time or in conception) creating Homo semejoticus, and thus bis paradifmatic conscientiae mentis captatio leading him to be and remain awere of this consciousness, history is accountable to our ego by beginninf with the analysis of speculations put forward by think rs who heve survived through records or any kind, including those made by hand (hand before voice, for recording, purposes, and thus the oldest historical 'tool', paradigmatically speaking). If I may be excused for borrowing, theoret:- 
cally, "nihil est in historia quod non est in documentatione," this pseudo-maxim is in practice the convention that each documentatio est minime duarum personarum consensus. History is, then, a social convention which was and is possible because of the existence of Homo semeioticus. Whether history exists in a social environment where one or more individuals has each his own conception of history is another matter. Although that view of history may be possible conceptually in, $3 a y, 2$ Aictator, a fool, or a genius, still this unique individual cannot divorce himself from the direct and indirect influence of a group (or at least one more person) in order to convey his sense of history. In essence, like language (or communication), history cannot exist in one single man. History is a social affair, and, as Croce maintained, always 'contemporary', except when conceived by self-appointed 'professional' historians. The contents of semiotic studies are strictly correlated with the thinkers who left records on their views about the sion. And there is no doubt that these thinkers are found in the very first records of mankind, be these records unrecoverable, or recoverable through 'written' language as well as through evidences that preceded any form of language as concelved by us now.

Boundaries, on the other hand, whether artificial or 'natural', are a product of Homo semeloticus. But at the very moment he conceived boundaries, he also learned how to 3 tay within or superate them. There are only two that are relevant 
for this preliminary essay: a function of (a) culture (geographical, institutional, etc.), and of (b) time within (a). As to culture, I comfortably and selfishly meander within the constraints of the 'west' as concocted by the Graeco-Poman tradition. For (b), the reasons are practical, not to say personal, as a consequence of the fact that, fortunately, I plan not to spend a thousand years on Planet Earth. The element of 'time', also, is to be connected with the records immediately available within (a). These are of several kinds: (i) philological (about twenty-six centuries for the GraecoRoman tradition); (ii) linguistic (50,000 years?); anthropological (two million years?); biological (how much time?). The question marks fust expressed above are indicative of the difficulty of time parameters. In this essay, I 'safely' prefer to stay within (1), though my degree of safety is only a state of mind, nothing more. ${ }^{1}$ Any other boundary in time (and consequently in space) undoubtedly deserves inquiries, but at present a time-boundary constraint on Earth can be only prorocative (see Jayness 1977 and cf. Time, March 24, 1977, 5153), while a space-boundary constraint is only temporary if one accepts at least two types: telepathic vs. extraterrestriol. (cf. Efron 1975).

Is for methodology, in semiotics there is an advantage. In developing, it for the writing of semiotics history, one can hardly expect to be coping with historlography. The field, thus, is clear of 'local' traditions, but one cannot ignore, 
at the same time, the traditions of other disciplines that are the product of applied semiotics. Two cases in point are philosophy and linguistics, though the former discipline commands a respect that linguistics can never dream of acquiring, for reasons due to contents and boundaries. Two things, however, both philosophy and linguistics have in common. At the beginning, of their histories, one cannot expect to speak of 'schools' but only of persons (more true for philosophy, which is at, the Poundation of ars grammatica). Thus, for philosophy, even at the time of Heraclitus, Parmenides, and Protagoras, one cannot convincingly place those scholars within a 'school', not even within a 'paradigm' of science history. As for lingufstics, many nore centuries have to go by before one can devise and impose the labels of schools to post-Thraxian activities which usually carry the name of either cities or philosophical doctrines.

The history of semiotics, then, up to the twentieth century, can be studied by analyzing the work of individual 'thinkers', although some correlation might be found with 'schools' or movements (or even 'centuries') where the label is carried by philosophy (e.g., post-Aristotelian) or by linvistics (e.g., grammatica speculativa). Luckily, the history of the twentieth century in matters semiotic is main?y a history of successful synthesis (Peirce), of elaboration (Morris), of dissemination (Sebeok), of re-analysis (Eco), and of application (from Kristeva, Koch, and Pelc to Bense, Borlssac, and 
Nattiez, to mention a very few in the most diverse field of epplied semiotics).

In essence, the history of semiotics par excellence might bepin at least with Heraclitus and continue with Hjelmsiev. It could also continue with anyone still alive and active in semiotics (and non-semiotics but approachinp, the biviumi). And this history, except for a few courageous fipures between these two points, is actually a history of missed opportunities. I shall try to venture into speculating that almost each and every time a thinker (In philosophy, linguistics, medicine, etc.) reaches a bivium in his speculations on the sign, he takes the 'wrong' turn or returns after probing and pondering, 'semiotics' in varying degrees.

The concept of the bivium neither stems from modem observations nor is a product of medieval speculations; it is classical. In Virgil (Aeneid, IX, 237-238), one reads: "...locum insidis conspeximus ipsi, qui patet in bivio portae, quae proxuma ponto...," where the bivium duas vias habet. It is found, as we11, in Livius and Plinius, emong others. Although the bivium is a location with two roads (ahead of the 'traveller'), it is also a place where two ways meet. The concept can be exterided to a point in time, also. In history, the blvium may arpear, suddenly or far in advance, in the life of an individual, be he a traveller or a thinker. It is also found by groups which split into factions and go in different ways. In the history of semiotics, some thinkers have often 
arrived at a bivium, but only a few have chosen the 'semiotic' road after abandoning the path of their main activity. Thus, to mention a few 'modern' speculators, with various defrees of interest in semiotics, one could select, say, Locke who abandoned medicine to become a philosopher at a certain bivium in his life. Peirce is a similar case in point, as he went through several bivia. In linguistics, de Saussure rejected law (and the family 'scientific' tradition) to study philology. Boas and Whorf encountered many bivia in bureaucratic activities to engage themselves in what later became American-Indian linguistics (per se or as a basis for theoretical linguistics). The list of examples could continue, especially if one includes cases from several disciplines interacting with semiotics and linguistics, for the thinking life of an individual is peppered with bivia. It happens, however, that it is in the field of linguistics, an offshoot of semiotics, that one finds most cases of 'wrong' turns, though similar turns are found as well in many other disciplines, from theology to literature. The history of science is replete with examples after the death of the 'univorsal' man in the Italian Renaissance. Only philosophy seems to Inhibit scholars, qua philosophers, from taking 'srong' turns. Once a onilosopher, always a philosopher, and thus, consclously or not, in constant plirt with semiotics.

My blitz excursus of twenty-five minutes will cover the feneral history of interaction between ars grammatica and ars semaiotica at the rate of one century per minute, hoping that 
it may still be possible to see how a change in airection was made by semiotici in potentia, some of whom still tower in the history of scholarship for other accomplishments. One could, first of all, artificially conceive five periods of interaction between linguistics and semiotics.

(1) The Graeco-Roman period containing, the seeds for ars semeiotica but turning to ars grammatica until Augustinus.

(2) The Middle Ages up to and including Dante, in which ars grammatica is gradually replaced by speculations in ars semeiotica.

(3) The Renaissance, ending with Campanella, oscillating between ars semeiotica and ars grammatica before reaching a synthesis.

(4) The 'modern' break, beginning with Locke and culninating with Peirce, in which general semiotics and general linguistics co-exist almost independently.

(5) The contemporary interplay between the two artes which paves the way to theoretical linguistics as a branch of applied semiotics, from de Saussure through HJelmslev and Jekobson to Anttila.

It should be borne in mind that the five perlods sketched above are not only highly subjective for illustrative reasons but also rather uncoordinated and uncorrelated with other trends or currents (as diverse as those of, say, Wittgenstein) that might constitute other periods or facets in the history 
cf semiotics, should this ever be written. Whether any bivium period' may coincide by chance with any historical semiotic period is not important here. I do not feel it is the case to mention 'paradigms' since I personally believe that in the history of semiotics there is only one paradigm--that of Heraclitus--and thus logically no paradigm at all since a paradigmatic history calls at least for one coupure éplstémologique between two paradioms. No one, so far, has broken the Heraclitean paradigm en principe, although Peirce might claim to have done it. This is perhaps impossible unless the original grasp of consciousness through the acquisition of the sign were destroyed in Homo semeioticus. But, then, semiotics (and its history) would also cease. Man is bivius by nature. This human quality of 'duality' is expressed in many ways and under different circumstances. For example, Varro, (De re rustica, I 18, 7) considers one aspect of Homo viaticus (figuratively, of course) by saying that "bivium nobis ad culturam dedit naturam, experientiam et imitationem." Here Varro refers, however, more to a point where two ways meet rather than one forking. still, the concept of the Homo bivius is among the classics. In classical times, covering the first period until Augustinus (if I may be allowed this stretching of 'classical' times), actually one cannot truly speak of a biyium for virlous rensons. First, there were no disciplines (tExual) properly 'compartmentalized' as they were later in the Middle Ages. fere I do not say, for instance, that a grammaticus might not 
have been different from a philosophus. I remember only that most frequently a philosopher was also a grammarian (if not that a grammarian was first a philosopher), but not often vice versa. This is particularly so for Greece where, especially in pre-Socratic times, a physician was also a philosopher, and could also be a literate, a psychologist, an astronomer, an historian, and so forth, at the same time. But this is what we now think of those scholars who did not classify themselves according to specific labels. Thus, the thinker was a Homo polyvius (or, better, universalis as seen later in Renaissance times), whose several roads took him to a merging point from different directions. It was a way of intellectual life, or travelling along roads that all led to knowledge and its expression. Only in the Renaissance, twenty centuries later, something similar to Graeco-Roman culture is reborn in and re-experienced by, say, a Michelangelo of whom one cannot say that he was a painter, an architect, a poet, or a sculptor.

The bivium, thus, is to be understood, in the first period, as one in which two or more 'ways' converge. But one of these ways is undoubtedly semiotic, for one can see travellers such as Heraclitus, Parmenides, Protagoras, Hippocrates, Socrates, Plato, Aristotle, Varro, Chrysippus, Quintilian, and Galenus, to mention only few who were enchanted, in varying degrees, by the role performed by the sign in the process that created Homo semeioticus. This is not the place 
to even sketch the contributions made by each of those scholars toward semiotic studies at a certain point in their lives. What is important is that, somewhere along their journey, they found themselves at a bivium. Just think what Aristotle, like Protagoras, would have given us if he had not opted for describing surface data on language in, say, his Poetica. It is known how each of these thinkers paused at the crossroad between 'semiotics' and 'linguistics' (or medicine, etc.), but the fork leading to speculation on the sign was only probed in varying degrees once, or several times, and then traced back to the fork in order to take to other path. The history of semiotics will, one day, explore the attempts made by several ancient scholars who, after delving into the nature and the function of the sign, were attracted by the grammatical trivialities culminating in Thrax' work. Others, like Varro, Quintilian, and Apollonius Dyscolus, were curious enouph to go along the semiotic path for a considerable distance. They, and the traditions they represented or instituted, paved the way to the triad formed by Philodemus, Sextus Empiricus, and Augustinus. (This triad is, again, a subjective one though it represents the end of a 'period' and at the same time a ink with what later became known as the Middle Ages.) Philodemus, in a way, is the primus inter pares amone the triad, but each member performs a different function. Although often and unjustly accused of marginalism, if not of Maiarism, Philodemus is a thinker that, at the bivium, 
defiritely disreferced ars grammatica, already implanted in Graeco-Roman tradition between Protaroras and Thrax, in order to select the semiotic prth. Philodemus' On Signs and Sem:osis is indeed an apologv to Epicurean empiricol method as well as a tool of demolition against the stoic rationalistic method. Thus, when arriving at the end of the third period, before embarking on the fourth one, it is necessary to remember Philodemus in order to understand the theory of signs expressed by Locke (and later thinkers).

Sextus Impiricus, insofar as semiotics is concerned, is revealed through his Outlines of Pyrrhonism, Against the Physicists, and, mainly, Against the Logicians, where the concept of semiosis appears as a mature one in the Philodemian tradition. Like Philodemus, Sextus Empiricus was not tempted by the secondary matters displayed by language. If he found himself at a bivium between ars grammatica and ars semeiotica, he chose the latter as a foundation for the former, after stressing the role of Homo semeioticus in society. For my assertion, it would suffice to review a couple of passages from his Adversus logicos. The first could be the section "De homine" in Book VII, especially paragraphs 269-272, where one can find the concepts later adapted and expanded by Cassirer and his antmal symbolicum, namely, paragrauh 269: "...homo est animal particeps rationis, morti obnoxium, capax intelligentiae et scientiae." As to his synthesis of past concepts on the sigr, in Book VIII, paragraph 241 inftiates the section 
"An sit aliquod signum," but one should at least proceed to the following section ("Quot sint non manifestarum rerum differentiae"), where paragraphs 201-211 illustrate his conception on the nature of the sign. Compare, however, the coeval cnlenus, not only for his Definitiones medicae, paragraphs XXVII ("Homo est animal rationale...") but for his Historia philosophica, Chapter IV ("De signo") according to the dialectical tradition. Augustinus, as Philodemus and Sextus Empiricus, when at the bivium, made several incursions along the semiotic path. In contemporary scholarship, his semiotic diversions have been sketched or illustrated by a few contemporary scholars (see Eschbach and Rader 1976:22-36), beginning with Markus 1957, but a comprehensive study of Augustinus semeioticus still awaits the seasoned scholar to place the African thinker in the proper intellectual climate. At any rate, Augustinus is consciously the first 'Western' thinker forced to select between one path and another, for, although there were several scholars before him engaged in semiotic activities, some like Philodemus never definitively went toward ars grammatice, as in the case of Apollonius Dyscolus. Had Angustinus, this, persisted in what we now consider semiotic studies, most probably he would not have been elevated to the honor of sanctity for converting the souls of Africans but would have baen studied by generations of students as a semioticist. Inlike the first period, where the bivium is a point of convergence, the second one is one of transition where sone 
thinkers 'converge' while others 'diverge'. In other words, in the early Midale Ages one witnesses the freezinf of activities into various artes as a reflection of disciplires seen even at the paedagogical level through the Trivium and the Quadrivium for the liberal arts. It is indeed the period that led to the institutionalization of formal instruction and, thus, the birth of European universities. In the first period a 'university' could not have existed as a concept because each thinker was a university unto himself. Both in Greece and Rome, 'schools', such as those philosophical, were more 'diachronic' than 'synchronic' since they tended to continue in time a certain doctrine originally born in one individual rather than in an institution (for example, Platonism - Augustinianism, for movements originated in an individual's name, or Stoicism born in Zeno and contiruing for the 'classical' period throughout Marcus Aurelius). At the beginning of this period, Boethius comes to surface for his interest in theories of signifying. But who would think of Boethius as a semioticist? Arain, Boethius at most can be labelled a theoretical musicologist or a logictan by those historlans who, like Deely 1976, go beyond the De consolatione philosophiae. On the other hand, after the impact $f$ the discovery and translations of Aristotle's work, the later Middle Ages show a convergence in the various activities and facets of the modi significandi, as illustrated by Bursill-4all 1971, but even there the very implication of 
(ars) grammatica through the term grammatica speculativa shows the influence if not the dominance of ars semeiotica upon the the gramatical tradition. This, in $a$ way, ends with Dante, who, especially in his early fourteenth century De Vulgari eloquentia, shows his concern for the role of the sign at the foundation of language. The concept of the sion exemplified by Dante still awaits a comprehensive study since it should be analyzed not only on the basis of the De Vulgari eloquentia but also throughout all his works showing, thus, an 'evolutionary' rearrangement of his concepts expressed in the Comedy.

The period between Boethius and Dante, thus, is the most fertile period for the exploration of the concept of the sign after the incubation of the first period. Both movements of convergence and divergence as indicated above, however, show that at the bivium some thinkers, l1ke the modistae, went all the way once they had taken the 'semiotic' fork. Cthers just probed the initial ramp of the non-ars grammatica path merely for de rigueur reasons that were introductory to other specuIations. One thing, nevertheless, comes to surface in the traffic selection at the bivium. The second period is definitely 'semiotic'. In fact, except partially for Priscian and his 'prammatical' tradition dominating the Middle Ages, a tradition being, an extension, an elaboration, and a translation' of the previous period, one can hardly speak of the 3.20 d period as one in which scholars took only the ars grammatica path at the bivium of the two artes. 
The third period, including, the Renaissance and extending. up to and including Campanella, is one of synthesfs. In essence, it synthesizes the elaborations of the second period. It is also that containing, one of the most intriguing, figures in the history of semiotics and linguistics: Campanella. It could be labelled the most humanistic sement of the entire semiotics history or the most semiotic segment of the entire humanities history, for the interaction between the humanities and semiotics leads to figures like Valla, Scaliger, Ramus, and, especially, Sanctius, normally studied in the history of linguistics. But these very figures are actually at the foundation of humanistic semiotics for each of them, whenever embarking on a trip for 'grammatical' purposes, was tempted by the bivium. Sanctius represents the Homo bivius par excellence in the post-Renaissance era. His bases for transformational syntax are laid only after his conception of the sign function has been first expressed. Surely, his ties are clearly postAristotelian, but his elaborations are unique in that he breaks with a tradition that was typically Thraxia whlle recapturing the seeds sewn by Apollonius Dyscolus via Priscian but definitely implanted in Quintilian's work. Sanctius at the same time ventures on to the semiotic path where he probes his concern for the nature of the sign. Unfortunately, he returns to the fork in order to proceed with his interest in the linguistic aspects of semiotics and not in its theory. Nevertheless, he shows his grasp of the sign function throughout the elaboration of his theory of syntax. 
While Sanctius remained along the linguistic trail, it was Campanella, the great unknown semioticist and 'universal grammarian', who definitely did not hesitate at the bivium to proceed along the path of the sign. Sooner or later, historians of semiotics will discover or uncover the contributions of Campanella and his influence not only on Dalgarno's Ars signorum but on a whole series of European thinkers culminating with John Locke and the Port Royal 'grammar'. To date there is only one study (Padley 1976) in which a systematic presentation of 'universal grammar' singles out Campanella who "anticipates Locke and Descartes" (p. 160). A reading of Padley 1976, the only objective and mature study on grammatical theory in Renaissance times appearing so far in this century, reveals his most acute observation regarding the semiotic foundations of grammar (p. 166).

The fourth period, between and including Locke and Peirce, is one of 'separation'. In other words, semioticists-and Inguists--go their own ways. This is more definitely so for linguists who, attracted by the terra incognita of comparative, historical, and general linguistics, starting at least with Fyarmathi 1799 , paid no attention to the foundations of lanvuage and concentrated on data external to it in terms of phonology and morphology. On the other hand, a whole series of scholars (Locke, Wolff, Lambert, Leibniz, down to Peirce) Cound themselves at a bivium where, in varying degrees, they prohed the semiotic foundation of linguistics after delving 
desultorily in 'surface' aspects of language data.

There is no question that both semioticists and Iinguists of this particular period do not interact. From Pask and Bopp to the neo-grammarians, the concern is not even minimally that of the sign. But already at the end of the nineteenth century, via general linguistics, on both sides of the Atlantic, a certain interest begins to be manifested in regard to the concept of the sign. A re-analysis of works by von Humboldt, von der Gabelentz, Wundt, even Max Müller, shows that language begins to be examined 'semiotically'. This leads to the last period in which German scholarship is reflected on the west bank of the Atlantic river via the linguistics of Whitney in synthesis with the first manifestation of the already mature American semiotic scholarship elaborated by Peirce. And this Peirce-Whitney tradition is reflected on and captured by de Saussure.

With the Swiss linguist, we are al ready in the fifth and last period where linguists begin to realize how this discipline is a branch of semiotics. De Saussure, after beine, confronted by many bivia, encountered the last one: semiotics vs. linguistics. He knew that at the foundation of linguistics there were semiotic implantations but was only able to announce and barely delineate his views in the first decade or so of our century. I feel that in his previous twenty-five years of silence, however, de Saussure must have pondered many times at the bivium. Was his selection of the linguistic road 
a consequence of his inability to accept the existence of sémiologie ("Puisq'elle n'existe pas encore...") or of his Loyalty to linguistics that had given him fame since his essay on Indo-Iuropean? There is no question that de Saussure understood the importance of the semiotic dimension of human language as a sine qua non for a comprehensive grasp of man's nature. But, when at the bivium, he took the 'wrong' turn and thus missed the opportunity of advancing semiotic studies. Ironically, de Saussure is known now for what he never felt he would be, 1.e., structuralism, a 'new' movement for a method of analysis that can be traced back to Heraclitus.

On the other hand, the opportunity missed by the Swiss scholar was seized by Hjelmslev who, like de Saussure, found himself at the bivium. But, unlike de Saussure, Hjelmslev-even acknowledging de Saussure's contributions probably either to tie himself to some paternity or for rensons of pietas-went beyond his putative master. Hjelmslev, in fact, when at the blvium, had no qualms in taking the semiotic turn, the first ever to be consciously taken by a linguist in the history of science.

It 1 s perhaps too early to assess the impact of Hjelmslev's accomplishments in semiotics, especially because of his scholarship being misunderstood in an age of structuralism and generativism within linguistics. In essence, while linguistics was and is still in the Thraxian paradigm psychologically, Hgelmslev's scholarship was and is an esoteric affalr (with a few 
exceptions, of course). Why? Becruse, first of all, Hgelmslev was considered a 'structuralist', which he was not in the 'linguistic' sense, especially because historians of linguistics unjustly equated the terms 'structural' with 'descriptive', at least since de Saussure worked with différences in structures (as later developed by the Prague school) while Hjelmslev operated with dépendances in functions (Hgelmslev 1961). That is why, in his Prolegomena, he writes as a semioticist with linguistics in his past while de Saussure spoke in the Cours as a linguist with semiotics in his future. Moreover, de Saussure never had the opportunity to 'sit down' and elaborate in writing the working of his conception. On the contrary, Hjelmslev, more fortunate, was able to draft, edit, re-edit a whole semiotic view of languape. If he also wrote 'linguistic' treatises for paedagogical reasons (such as Hfelmslev 1970), so distant from his theoretical work (Hjelmslev 1975), the reason is simple: he was teaching linguistics in an age when language studies were concerning with 'surface' data as they were in Aristotle's time, and not in Protagoras' time.

This last period, thus, witnesses a beginning of a new consciousness among linguists and non-linguists. Even Morris, for example, was close to the tendencies exemplified by the period of Bloomfield, Sapir, and de Andrade. Bloomfield, although rejecting the non-scientific scholarship of Dionysius Thrax in practice, was in theory a product of Dionysius Thrax 


\section{$-? 21-$}

himself. Sapir was, unlike Bloomfield, a humanistic linguist via his interest in applied semiotics, such as poetry and music. De Andrade, had he not died so young, might have been the American counterpart to the Danish linguist. But Morris, the philosopher, though confronted with the bivium, went 'semiotic' all the way in an age of dazzling linguistics.

I would like to conclude my remarks, mostly impromptu, by mentioning the case of Roman Jakobson at the bivium. I feel that Jakobson will probably go down in history under the label of 'linguist'. But is Jakobson a linguist or a semioticist? The advantage of living a lonp, life, at times, leads to a bivium. There is no question that Jakohson has worked all his life as a Iinguist, but I feel that his latest activities reveal a scholar who actually thinks like a semioticist. Since he is still alive (and the way he has planned his current work points to a long life), I refrain from predicting. I only know, however, that he is already past the bivium and along the semiotic path, fudging by his latest essay, decisively semiotic, and especially so since his "Language in relation to other Commication Systems" (Jakobson 1970) culminating in his Coup d'oeil sur le développement de la sémiotique (Jakobson 1975).

Will the bivium become irrelevant one day? I feel so. Already there are many indications. The breakthrough has already occurred in Anttila 1972, the first and only linguist to establish a methodology of historical linguistics on peirce's thenmy of the sign. When I first used this book as a taxt in 
course on historical linguistics, students were bewildered, especially those exposed, as I had been, to philolosical and historical methods (whether structural or transformational). A colleague of mine called it "dull". A recent article in Forum Linguisticum (Shaumyan 1976) on "Linguistics as part of Semiotics" shows another trend, especially notable as it comes from a scholar known throughout the world as a linmuist. Finally, I would like to sum up my conclusions with one hope. Since you and I are interested in Ianguage studies, would it be too risky to assume that actually the appearance of a bivium in the scholarly life of an individual is the healthiest thing? Or should I venture to declare that a scholar without a bivium is no scholar at all? 


\section{NOTES}

1. For exciting speculations involving question marks-the first invention of Homo semeioticus after concelving the lie--one could start with the latest effort, e.g., either YcCormack and Wurm (1976) as a synthesis or a more optimistic enterprise displayed by the periodical contributions in Totus Homo. For the concept of Homo semeloticus, see Romeo 1977. 
RFFFRENCES

Anttila, Paimo. 1972. An Introduction to Historical and Comparative Linguistics. New York: Macmillan.

Bursill-Hall, G.L. 1971. Speculative Grammars of the Middle Ages. The Haque: Mouton.

Deely, John N. 1976. "The Doctrine of Signs: Takinf, Form at Last," Semiotica, 18:2:171-193.

Efron, David. 1975. "Semiotics and Telepathy," Versus: Quaderni di studi semiotici, 12:4:109-116.

Hjelmslev, Touis. 1961. Prolegomena to a Theory of Lancuage. Trans. F. J. Whitfield. Madison: University of hisconsin Press.

- 1970. Laneuage: An Introduction. F. T. Whitfield. Madison: Iniversity of Wisconsin Press.

- 1975. Résumé of a Theory of Language. Ed. and trans. with Introduction by F. J. Whitfiled. Yadison: University of Wisconsin Press.

Takobson, Roman. 1970. "Language in Relation to other Communication systems" in VV.AA., 1970:3-16.

- Coup d'oeil sur le développement de la sémiotique $($ = Studies in Semiotics, 3). Bloominaton: Indiana University Publications.

Jayness, Julian. 1977. The Origin of Consciousness in the Breakdown of the Bicameral Mind. New York: Houghton Mifflin.

McCormack, W. C. and S. A. Wurm (eds.). 1976. Language and Man: Anthropological Issues. $[=9$ th International Confress of Anthropological and Ethnological Sciences, Chicapo, 1973.J The Hague: Mouton.

Padiey, G. A. 2976. Aremmatical Theory in Western Europe, 1500-1700. The Lat in Tradition. Cambridge: University Press.

Romeo, Luipi. 1977. "The Semiotic Foundations of Linguistics." Semiotic Scene $[=$ Bulletin of the Semiotic Society of America:, I, 2, 31-38.

Sebeok, Thomas A. 1977. "The Semiotic Web: A Chronicle of Prequdices" in Sebeok 1077a:149-188. 
-1977a. Contributions to the Doctrine of Signs.

( = Studies in Semiotics, 5.) Bloomington: Indiana University.

Sextus Empiricus. 1841. Opera graece et latine. Vol. 2. Lipsiae: Sumptu Librariae Kuehnianae.

Shaumyan, Sebastian. 1976. "Linguistics as Part of Semiotics," Forum Linguisticum, I, 1:60-66.

VV.AA. 1970. Linguaggi nella società e nella tecnica. Milano: Edizioni di Comunita. 